\title{
Nutrition knowledge, dietary patterns and anthropometric indices of older persons in four peri-urban communities in Ga West municipality, Ghana
}

\author{
Faith Agbozo ${ }^{1}$, Joyce Amardi-Mfoafo², Helen Dwase ${ }^{2}$, Basma Ellahi ${ }^{3}$
}

1. Department of Family and Community Health, School of Public Health, University of Health and Allied Sciences, Ho, Ghana.

2. Department of Family and Consumer Sciences, College of Agriculture and Consumer Sciences, University of Ghana, Legon, Accra.

3. Faculty of Health and Social Care, University of Chester, Chester, CH1 4BJ, UK.

\begin{abstract}
Background: Older adults are vulnerable to malnutrition due to sociologic, physiologic and anatomical effects of ageing.

Objective: To investigate the influence of nutrition knowledge and dietary patterns on nutritional status of community-dwelling ambulatory older adults.

Methods: This cross-sectional survey involved 120 elderly aged 60-70 years purposively selected from four peri-urban communities in Ga West municipality, Ghana. Nutrition knowledge was assessed using a structured questionnaire and dietary intakes obtained using a standardized food frequency questionnaire. BMI from weight/height measurements was proxy for nutritional status. Data was analyzed descriptively in SPSS. Associations were tested using correlation analyses $(-1<\mathrm{r}<+1)$.

Results: $28 \%$ had adequate knowledge on geriatric nutrition. Dietary patterns were mostly fair (40\%) or poor (53\%). Bloating $(25 \%)$, constipation (18\%), appetite loss $(12 \%)$ and chewing difficulties $(11 \%)$ affected intakes. Underweight was $10 \%$ while $21.7 \%$ were overweight or obese $(16.6 \%)$. Positive insignificant corrections existed between knowledge and nutritional status $(\mathrm{r}=0.261)$ and with diet quality $(\mathrm{r}=0.415)$. However, strong significant $(\mathrm{p}=0.027)$ positive correlation $(\mathrm{r}=0.699)$ existed between diet quality and nutritional status.

Conclusion: Nutrition knowledge was adequate but dietary intake was poor and a quarter were malnourished. The associations reaffirm that supporting the elderly to make healthy dietary choices and ensuring household food security is crucial to preventing malnutrition.

Keywords: Dietary knowledge, food diversity, body mass index, elderly, geriatric nutrition.

DOI: https://dx.doi.org/10.4314/ahs.v18i3.33

Cite as: Agbozo F, Amardi-Mfoafo J, Dwase H, Ellabi B. Nutrition knowledge, dietary patterns and anthropometric indices of older persons in fourperi-urban communities in Ga West municipality, Ghana. Afri Health Sci. 2018;18(3): 743-755. bttps:/ / dx.doi.org/10.4314/ahs.v18i3.33
\end{abstract}

\section{Introduction}

Life expectancy has increased due to advancement in medicine, paramedical sciences and technology ${ }^{1}$. By 2050,

\section{Corresponding author:}

Faith Agbozo,

Department of Family and Community Health, School of Public Health, University of

Health and Allied Sciences, Ho, Ghana;

PMB 31, Ho, Ghana

Email: faagbozo@uhas.edu.gh the proportion of the world's population $>60$ years will double to $22 \%{ }^{2}$. This rapid demographic change will be evident in low and middle-income countries ${ }^{3}$. In Ghana, between 1960 and 2010, the population of the elderly increased by more than seven-folds with 1,643,381 persons out of the total $24,658,823$ Ghanaian population above the age of 60 years. This is projected to increase from $5.3 \%$ to $8.9 \%$ by $2050^{4}$. The WHO defines older persons, traditionally called the elderly, as persons who have reached the age of retirement. The elderly are categorized into three age groups: 'young old' (60-74); 'old old' (7584); and 'oldest old' ( $\geq 85$ years $)^{5}$. 
Good nutrition is particularly important to older persons because of the physiological changes that occur in the body as one ages. Poor diets contribute to frailty, complicating functional limitations and leading to loss of muscle mass, metabolic abnormalities and diminished immunity ${ }^{6}$. Adequate diet and optimum nutritional status play a critical role in maintaining immune response of the aged by promoting resistance to infection and other immune-related diseases ${ }^{7}$. The functional capacity and health of the older person depends on their nutritional status and food security, which are the cornerstone in determining nutritional well-being ${ }^{8,9}$. However, older persons are most unlikely to eat balanced diets to meet the nutrient needs of their changing physiologic state ${ }^{10,11}$. This makes them vulnerable to malnutrition with the associated poor health outcomes.

Globally, malnutrition rates in older persons vary based on the screening tools used, whether the study population is community (free) living or institutionalized as well as the geographic location. Using the Mini Nutritional Assessment tool, the prevalence of malnutrition in Italy was $26 \%$ among females and $16.3 \%$ in males ${ }^{12}$. In Iran, $10.3 \%$ of the elderly residents in nursing homes were malnourished $^{13}$. In The Netherlands, Germany and Austria, the prevalence were $18.3 \%, 20.1 \%$ and $22.5 \%$ respectively ${ }^{14}$. In the Lake Victoria Basin in East Africa, $26.4 \%$ of the elderly were underweight while $15.3 \%$ were overweight/ obese $^{15}$.

In rural Ghana, a $41 \%$ underweight and $16.9 \%$ overweight/obesity prevalence has been observed among elderly women aged 60 to 92 years ${ }^{16}$. The overall prevalence of undernutrition among older persons in sub-Saharan Africa varies across countries ranging from $5 \%$ in South Africa to $48 \%$ in Ghana making Ghana one of the countries in sub-Saharan Africa with a high burden of malnutrition ( $>40 \%$ ) among the elderly population ${ }^{11,16,17}$. The high prevalence of malnutrition among older persons in Ghana though a worrying trend is not surprising as in the national capital Accra, only $39.1 \%$ of the elderly have been found to be food secure ${ }^{18}$.

Major health problems for which older adults seek care in health facilities in Ghana are hypertension, stroke, di- abetes and osteoarthritis ${ }^{19,20}$. Most of these diseases have underlying nutrition-related causes. Also, due to ongoing nutrition and epidemiological transition in Ghana, wealthy and urban communities are at higher risk of obesity and chronic diseases whereas poor and rural communities are at higher risk of undernutrition, infections as well as chronic diseases ${ }^{20,21}$. Nutritional intervention programmes such as dietary counseling and nutrient supplements could improve nutritional status ${ }^{22-24}$. Adequate diets and healthy dietary patterns improve nutritional status ${ }^{10}$, decreases risk of nutrition-related chronic diseases associated with cognitive decline ${ }^{25}$, reduce morbidity and mortality and increase longevity ${ }^{26}$. Nonetheless, dietary intakes of most older persons have been shown to be of poor quality ${ }^{27,28}$. Also, nutrition knowledge of most older persons is poor ${ }^{29}$ and usually weakly associated with dietary intakes thereby not translating in optimum nutritional status ${ }^{30}$.

Studies on malnutrition among the elderly in Ghana have concentrated in urban areas ${ }^{17,18}$ with few conducted in rural communities ${ }^{16}$. Due to urbanization with its associated rapid expansion of cities, hitherto rural communities located at peripheries of big cities are transiting into cosmopolitan areas. The elderly are the most affected by increased complexity of communities, hence the need to focus on peri-urban elderly dwellers. This study assessed the level of nutrition knowledge, dietary patterns and food choices, and anthropometric indices of the elderly. The existence of associations among these nutritional status indicators was also tested.

\section{Materials and methods Study setting}

The study was conducted in the Ga West municipality, one of the 16 administrative districts located in the north-western end of the Greater Accra Region, Ghana. The municipality occupies a land area of approximately 300 square kilometres and comprises 219,788 inhabitants. Out of these, $4.3 \%$ are above the age of 60 years with females constituting $56 \%{ }^{31}$. The four largest peri-urban communities in the municipality (Pokuase, Amasamnan, Medie and Ofankor) were all part of the study setting. Hitherto, care of the aging population was a collective 
role shared by the extended family. Now, the nuclear family particularly children are the forefront care providers. Socio-economic, urbanization and demographic transitions have affected dynamics of the traditional family system. Increasingly, the elderly are responsible for carrying out their everyday tasks due to decreasing social support. Although aged care services are becoming common in Ghana, at the time of conducting this study, there were no such facilities in the Ga West municipality.

\section{Study design and target population}

The study was a descriptive cross sectional observational household survey. The target population was all "young old" adults age 60 to 70 years. An upper limit of 70 years was set because the study protocol involved recall of dietary intakes as well as the taking of anthropometric measurements. Ability to stand upright and memory accuracy were crucial since anatomical functioning and cognitive have been shown to reduce with advancing age $e^{6,32}$.

\section{Sample size and sampling procedure}

In the Ga West municipality, adults aged $60-70$ years constitute $2.5 \%(5,595)$ of the total municipal population ${ }^{31}$. With the aid of Cochran's formula ${ }^{33}$, using the population size of 5,595 at $95 \%$ confidence level ( $5 \%$ error margin), 1.96 alpha, 7 and $17 \%$ prevalence of undernutrition among the elderly ${ }^{16}$, this generated a sample size of 109 . Allocating $10 \%$ for missing and incomplete data, the final sample size recruited was 120 . Thirty participants were allocated to each of the four study communities. Inclusion criteria were age limits of 60 and 70 years, ambulatory, ability to stand upright and free will to decide on what to eat. Interviewers were assigned to the north, south, east and west ends of each study community and moved inwards towards the central part. The first house to be visited was determined by a random walk and the zigzag principle followed thereafter. Respondent were primarily purposively selected. Where there was difficulty getting eligible participants, subsequent recruitments were made using the snowball sampling procedure.

\section{Data collection and analyses}

A structured questionnaire containing open and closed ended questions was used to collect information on respondents' socio-demographic data, dietary intakes and nutrition knowledge. The questionnaire was translated into $\mathrm{Ga}$ and Akan, the two predominate local languages spoken in the study area. Data generated was hand-coded and entered into the SPSS software (version 20) to generate frequency and percentage distributions. Spearman rank-order correlation coefficient ( $r$ ) statistic was used to measure the strength and direction of association between two ranked variables involving either nutrition knowledge, dietary patterns or nutritional status. These variables were categorized as ordinal data and the monotonic relationship between the permutated variables were determined using $-1<\mathrm{r}<+1$ at $5 \%$ level of significance $(\mathrm{p}<0.05)$. Correlation coefficient $<0.5$ implied a weak association, $>0.5$ implied a strong association, $r=0.0$ implied no association whilst $\mathrm{r}=1.0$ signified a perfect correlation.

\section{Nutrition knowledge}

Due to the absence of a validated nutrition knowledge questionnaire suitable for the local context, a nutrition knowledge questionnaire was specifically designed to achieve our objectives. However, it was standardized in accordance with the format of knowledge assessment questionnaires used in similar studies. Issues tackled centered on nutrients; health benefits of food; the diet-disease relationship; fruits and vegetables; water; and physical activity. In the questionnaire were ten nutrition-related thematic sub-sections on a five-point rating scale ranging from strongly agree, agree, neutral, disagree to strongly disagree. For each statement, scores ranging from zero to five were assigned to the appropriate response category. Total knowledge scores were calculated with highest and lowest possible scores of 50 and 10 respectively. Based on the minimum and maximum ranges of the aggregate knowledge scores as well as the mean and median values of the distribution, nutrition knowledge was categorized and rated as good if the aggregate score was from 36-50, satisfactory if the aggregate score was from 20-35 and poor if the aggregate score was less than 20 scores.

\section{Dietary patterns, diversity and quality}

A food frequency questionnaire (FFQ) comprising seven major food groups with frequency of consumption categories was used to collect qualitative information on the usual food consumption patterns of participants to deter- 
mine the diet quality and diversity. The seven major food groups from which meals were prepared on daily basis in Ghana are cereals and grains; roots tubers and plantain; animal products; vegetables; fruits; legumes nuts and oily seeds; and fats and oils. The dietary diversity scores were determined on the basis of adequacy of daily intake of foods from the seven food groups. Diets that included at least one food item from either six or seven of the food groups were rated as adequate; diets that included food items from five out of the seven food groups were rated as fair diets whereas diets that included food items from four or less food groups were rated as poor.

\section{Nutritional status}

Standing height and weight was measured using 'SECA' stadiometre and digital weighing scale to the nearest 0.1 centimetres and 0.1 kilogram respectively. The anthropometric measurements were used to calculate participant's body mass index (BMI) as weight in kilogram divided by height in meters squared. The BMI were classified and in- terpreted according to WHO age and sex specific guidelines and used as proxy to determine nutritional status: underweight $\left(<18.5 \mathrm{kgm}^{2}\right)$, normal weight (18.50-24.9 $\left.\mathrm{kg} / \mathrm{m}^{2}\right)$, overweight $\left(\geq 25.0-29.9 \mathrm{~kg} / \mathrm{m}^{2}\right)$ and obese $(\geq 30.0$ $\left.\mathrm{kg} / \mathrm{m}^{2}\right)^{34}$.

\section{Results}

\section{Background characteristics of study respondents}

One hundred and twenty participants were recruited comprising 78 females and 42 males. Table 1 shows their socio-demographic characteristics.

Nearly $60 \%$ were aged between 60 and 65 years. Sixty percent had little or no formal education. Ninety percent were Christians while the rest were either Muslims (7\%) or traditionalist. Although a third of the participants were not engaged in any income generating activity, they all had subsistence either from a regular job, pension benefits or as financial support from family and friends. Forty percent lived alone, a third with their spouses while the remaining proportion lived with their children and other family members. 
Table 1. Socio-demographic characteristics of study participants

\begin{tabular}{|c|c|c|}
\hline Background characteristics & $\mathrm{N}=120$ & $\%$ \\
\hline \multicolumn{3}{|l|}{ Sex } \\
\hline Females & 78 & 65.0 \\
\hline Males & 42 & 35.0 \\
\hline \multicolumn{3}{|l|}{ Age (years) } \\
\hline $60-65$ & 71 & 59.2 \\
\hline $66-70$ & 49 & 40.8 \\
\hline \multicolumn{3}{|l|}{ Educational Level } \\
\hline None & 54 & 45.0 \\
\hline Elementary School & 18 & 15.0 \\
\hline Middle School & 26 & 21.6 \\
\hline Secondary/Technical/Vocational & 11 & 9.2 \\
\hline Tertiary & 11 & 9.2 \\
\hline \multicolumn{3}{|l|}{ Religious affiliation } \\
\hline Christian & 107 & 90.0 \\
\hline Others * & 13 & 10.0 \\
\hline \multicolumn{3}{|l|}{ Income generating activities engaged in } \\
\hline Trading & 53 & 44.1 \\
\hline Artisanal work $\dagger$ & 18 & 15.0 \\
\hline Farming & 11 & 9.2 \\
\hline None & 38 & 31.7 \\
\hline \multicolumn{3}{|l|}{ Source of income for livelihood $\ddagger$} \\
\hline Money earned from income-generated activities & 83 & 45.0 \\
\hline Money from children & 48 & 34.3 \\
\hline Pension allowance & 15 & 10.7 \\
\hline $\begin{array}{l}\text { Financial support from other relations and } \\
\text { friends }\end{array}$ & 14 & 9.1 \\
\hline \multicolumn{3}{|l|}{ Person with whom respondent resided } \\
\hline Alone & 48 & 40.0 \\
\hline Spouse & 41 & 34.3 \\
\hline Children & 24 & 20.0 \\
\hline Other family members & 7 & 6.0 \\
\hline
\end{tabular}

Nutrition and health related knowledge of respondents

From ten statements used to assess nutrition knowledge, $38 \%$ of the participants believed that it was necessary to drink water only when thirsty. Most (74\%) agreed that a healthy diet was one that contained varied foods necessary to meet an individual's nutrient requirements. Thir- ty percent thought that with advancing age, physical activity should be reduced. Almost half (47.6\%) felt that constipation occurred as result of ageing and the use of laxatives was the way out. Almost $90 \%$ knew that daily consumption of fruits and vegetables promotes health. Also, $55 \%$ thought it was necessary for the elderly to take nutrient supplements routinely to complement their diets. 
Most $(72 \%)$ of the participants agreed that nutrition was pivotal in the prevention of diseases and the promotion of health. In relation to intake of protein-rich foods, 33\% disagreed that older persons required high quantities of protein for growth and maintenance of body tissues. Seventy percent agreed with the statement that obese people could be malnourished and $75 \%$ believed that older persons could skip meals if they lose appetite.

From the aggregate knowledge ratings, 5.8\% of the respondents scored below 10, indicating poor nutrition knowledge; $65.8 \%$ scored from $20-35$, indicating satisfactory nutrition knowledge whereas $28.3 \%$ had cumulative score above 35 , indicating good nutrition knowledge.

Dietary patterns, diversity and diet quality of respondents

Dietary habits and dietary-related challenges experienced by the respondents are presented in table 2 . Half cited hunger as the primary reason for eating and a further $37.5 \%$ mentioned health and vitality. Nearly half (47\%) prepared their own meals while $46 \%$ had their meals prepared by either their wives or children. Over $90 \%$ ate two to three times a day with a little over half eating three meals daily. Most $(66 \%)$ of these meals were usually home-prepared. The most influential factors affecting respondents' food choices were appetite (43.9\%) and availability of food $(33.3 \%)$. More than half of the respondents routinely took supplements in the form of iron and multivitamins tablets and herbal supplements. A quarter (25.8\%) avoided foods such as cassava, snails, okra and beans. Although 12\% did not complain of any problems associated with eating, the majority contended mainly with stomach bloating (28\%), constipation (18\%), loss of appetite, difficulty chewing and bitterness in the mouth. Diagnosed dietary-related medical conditions included osteoarthritis, cardiovascular diseases (hypertension \& stroke), dental problems, diabetes mellitus and stomach ulcer. 
Table 2. Eating habits, well-being and diet quality of participants

\begin{tabular}{|c|c|c|}
\hline Characteristics & $\mathbf{N}$ & $\%$ \\
\hline \multicolumn{3}{|l|}{ Reasons for eating } \\
\hline Hunger satiety & 52 & 49.2 \\
\hline Health and vitality & 45 & 37.5 \\
\hline Growth and longevity & 13 & 10.8 \\
\hline \multicolumn{3}{|l|}{ Person responsible for meal preparation } \\
\hline Respondent & 56 & 46.7 \\
\hline Wife & 30 & 25.0 \\
\hline Children & 25 & 20.8 \\
\hline Other relations & 9 & 7.5 \\
\hline \multicolumn{3}{|l|}{ Number of times respondents ate per day } \\
\hline Two times & 49 & 40.8 \\
\hline Three times & 63 & 52.5 \\
\hline Four times & 8 & 6.7 \\
\hline \multicolumn{3}{|l|}{ Usual source of meals } \\
\hline Home prepared & 79 & 65.9 \\
\hline Purchased & 41 & 34.1 \\
\hline \multicolumn{3}{|l|}{ Factors influencing respondents' food choices } \\
\hline Appetite \& hunger & 53 & 43.9 \\
\hline Availability of food & 40 & 33.3 \\
\hline Availability of money & 17 & 13.9 \\
\hline No particular reason & 10 & 8.9 \\
\hline \multicolumn{3}{|l|}{ Routine intake of nutrient supplements } \\
\hline Yes & 66 & 55.0 \\
\hline No & 54 & 45.0 \\
\hline \multicolumn{3}{|l|}{ Food allergies } \\
\hline Yes $*$ & 31 & 25.8 \\
\hline No & 89 & 74.2 \\
\hline \multicolumn{3}{|l|}{ Health problems associated with eating $\dagger$} \\
\hline Gastrointestinal gas & 61 & 24.7 \\
\hline Constipation & 44 & 17.8 \\
\hline Loss of appetite & 28 & 11.3 \\
\hline Difficulty chewing & 26 & 10.5 \\
\hline Bitterness in the mouth & 26 & 10.5 \\
\hline Diarrhoea & 20 & 8.1 \\
\hline \multicolumn{3}{|l|}{ Diagnosed medical conditions $†$} \\
\hline Osteoarthritis & 35 & 19.0 \\
\hline Visual impairment & 35 & 19.0 \\
\hline Cardiovascular diseases (hypertension \& stroke) & 30 & 16.3 \\
\hline Dental problems & 24 & 13.0 \\
\hline Hearing impairment & 15 & 8.2 \\
\hline Diabetes mellitus & 13 & 7.1 \\
\hline Stomach ulcer & 13 & 7.1 \\
\hline \multicolumn{3}{|l|}{ Healthy habits $\ddagger$} \\
\hline Fruit consumption & 41 & 34.2 \\
\hline Physical activity & 37 & 30.8 \\
\hline \multicolumn{3}{|l|}{ Unhealthy habits $\neq$} \\
\hline Alcohol consumption & 15 & 12.5 \\
\hline Tobacco smoking & 9 & 7.5 \\
\hline High salt intake & 6 & 5.0 \\
\hline \multicolumn{3}{|l|}{ Diet quality } \\
\hline Adequate & 8 & 6.7 \\
\hline Fair & 48 & 40.0 \\
\hline Poor & 64 & 53.3 \\
\hline
\end{tabular}

${ }^{*}$ Common allergens: cassava, snails, okra, beans and pork. tData generated from multiple responses. $*$ Habits were indulged in at least three times per week. "Dietary quality was determined based on adequacy of intake of foods from seven food groups daily. Diets that included foods from 6-7 food groups were rated as adequate; diets that included foods from 5 groups were rated as fair whilst diets that included foods from $\leq 4$ groups were rated as poor. 
Dietary diversity of the respondents is shown in figure 1. On a daily basis, most frequently consumed foods were tomatoes $(97 \%)$, onions $(95 \%)$ and pepper $(85 \%)$. This was followed by bread (78\%), fish (76\%); maize (67\%), green leafy vegetables $(66 \%)$ and palm oil $(66 \%)$. Over half consumed rice $(54 \%)$, plantain $(52 \%)$ and cowpeas (48\%); whereas approximately $40 \%$ consumed cassava $(40 \%)$, milk (39\%) and groundnuts (39\%). Apart from oranges that were consumed by half of the respondents on a daily basis, only a quarter ate any other fruits in a day. Respondents' diet quality was determined based on the adequacy of daily intake of foods from the seven food groups. Only $6.7 \%$ consumed foods from six or all seven food groups daily and therefore met the criteria for adequate diet. Dietary intake of $40 \%$ was rated as fair quality because daily, the diets included foods from five out of the seven food groups. Half (53.3\%) consumed poor quality diets as less than five food groups were included in their meals on daily basis.

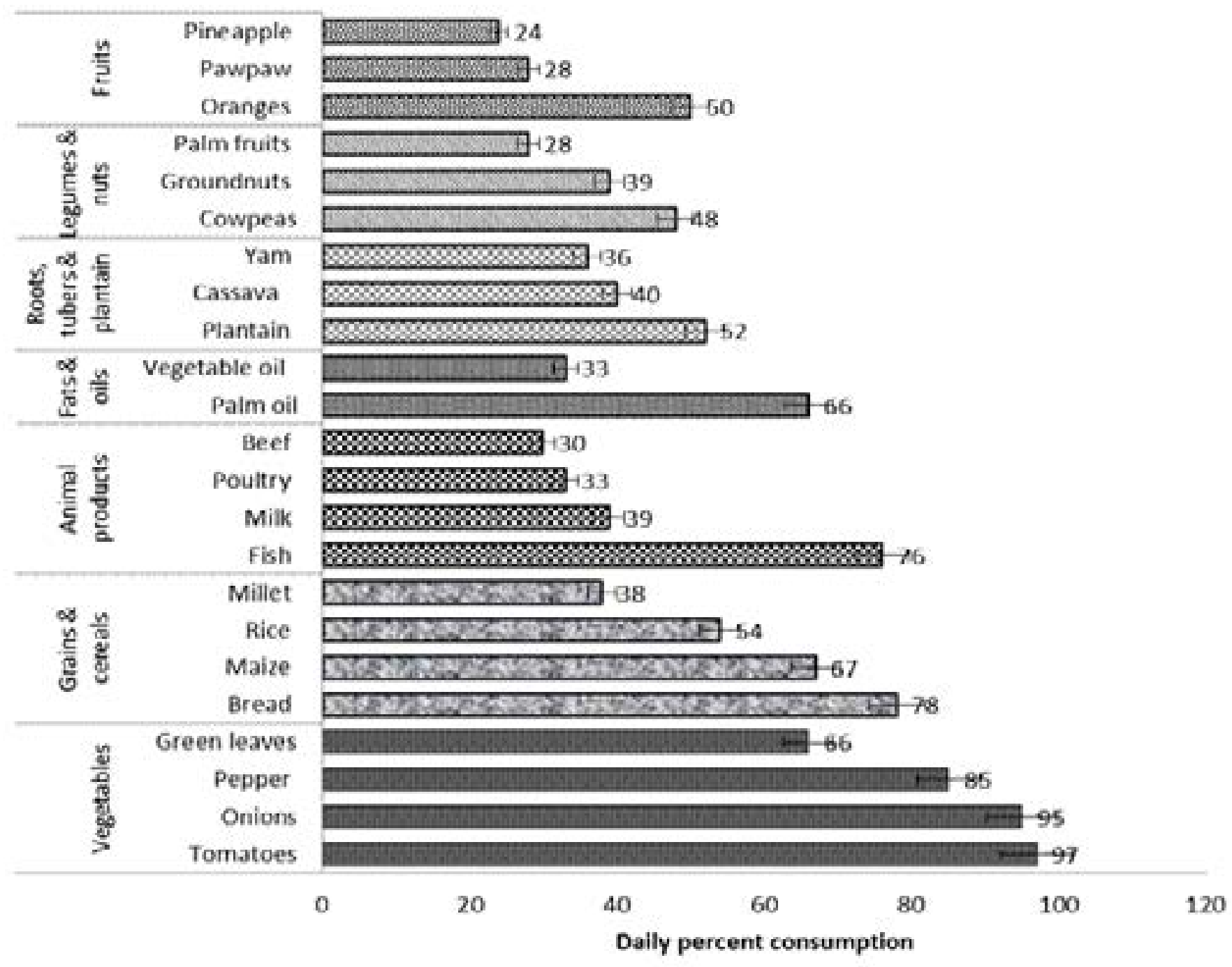

Figure 1. Daily percentage frequency of consumption of food items from seven food groups

\section{Nutritional status of respondents}

The BMI of half $(51.7 \%)$ of the respondents was normal; $10.0 \%$ were underweight; $21.7 \%$ were overweight whereas $16.6 \%$ were obese.
Correlation between nutrition knowledge, diet quality and nutritional status

Table 3 reveals that the correlation between nutrition knowledge and nutritional status was weak positive 
$(\mathrm{r}=0.261)$ but insignificant $(\mathrm{p}=0.352)$. Similarly, there was an insignificant positive correlation $(\mathrm{r}=0.415)$ between nutrition knowledge and diet quality $(\mathrm{p}=0.792)$. How- ever, a significant $(\mathrm{p}=0.027)$ strong positive correlation $(\mathrm{r}=0.699)$ was observed between diet quality and nutritional status.

\section{Table 3. Correlation of nutrition knowledge, diet quality and nutritional status}

\begin{tabular}{|c|c|c|c|c|}
\hline Variable & $\%(\mathrm{~N})$ & Variable & Correlation*coefficient & $P$ paluet \\
\hline Nutrition knowledge * & & BMI levels & 0.261 & 0.352 \\
\hline Good & $28.3(34)$ & & & \\
\hline Satisfactory & $65.8(79)$ & & & \\
\hline Poor & $5.8(7)$ & & & \\
\hline Dietary intakes $\dagger$ & & $\begin{array}{l}\text { Nutrition } \\
\text { knowledge }\end{array}$ & 0.415 & 0.792 \\
\hline Adequate & $6.7(8)$ & & & \\
\hline Fair & $40.0(48)$ & & & \\
\hline Poor & $53.3(64)$ & & & \\
\hline BMI levels $\ddagger$ & & Dietary intakes & 0.699 & 0.027 \\
\hline Underweight & $10.0(12)$ & & & \\
\hline Normal & $51.7(62)$ & & & \\
\hline Overweight & $21.7(26)$ & & & \\
\hline Obese & $16.6(20)$ & & & \\
\hline
\end{tabular}

${ }^{*}$ Derived from responses given to nutrition knowledge-related statements and aggregate scores categorized as: good (36-50); fair (20-35); and poor (<20). tDetermined based on adequacy of intake of foods from seven food groups daily. Diets that included foods from 6-7 food groups were rated as adequate; diets that included foods from 5 groups were rated as fair whilst diets that included foods from $\leq 4$ groups were rated as poor. 勘y mass index classified as underweight (BMI<18.49), overweight (BMI 25.00-29.9) and obesity $($ BMI $>29.99)$

\section{Discussion}

Over $90 \%$ of participants had satisfactory to good nutrition knowledge. This was contrary to studies in India and Taiwan where nutrition knowledge of urban and rural elderly was mainly unsatisfactory ${ }^{20,35}$. In China however, almost half of respondents had good knowledge of nutrition and health ${ }^{36}$. In this study, although respondents' knowledge on daily water intake, constituents of a healthy diet, importance of physical activity and consumption of fruits and vegetables was particularly good, responses on intake of protein-rich foods, causes and remedy for constipation, meal skipping as result loss of appetite, warrant attention. Higher educational level and living in less remote areas are shown to correlate with nutrition knowledge $\mathrm{e}^{25,29,36}$. Although the majority of study participants received no formal education, residency in a peri-urban setting might be advantageous due to better access to information and healthcare. It is worth noting that social and health interventions in Ghana targeted at the elderly such as free registration unto the National Health Insurance Scheme and the establishment of geriatric unit at out-patient department of hospitals provide an avenue for improved healthcare delivery through client counselling on healthy lifestyles. This could contribute to the good nutrition knowledge demonstrated by the study participants. 
Regarding dietary patterns, apart from vegetables and grains/cereals, fish was the most consumed on daily basis. These three food groups have been found to be the highest contributors of daily meals in several places ${ }^{10,37,38}$. Diet quality of more than half of the respondents was poor. Similar results have been found in other studies ${ }^{27,28}$. A lot of factors affect the quality of diets of older persons and consequently, their nutrition and health status. The positive determinants include education, nutrition knowledge, availability of money, number of daily meals eaten, perceived physical health, and hunger sensation. The negative determinants are living alone, alcohol consumption, dental problems and regular eating outside the home ${ }^{28,39-41}$. From this study, proportion of respondents without any formal education, no guaranteed source of income, who lived alone, prepared their own meals, ate outside home and drink alcohol were fairly high. Living alone for instance, have been associated with meal skipping, obesity, underweight and unhealthy eating behaviors ${ }^{41}$. While appetite and hunger sensations decline with age ${ }^{42}$, increased food preferences affect older person's food choices and hence their dietary patterns. Most $(>90 \%)$ of the respondents ate two to three times a day with a little over half eating three meals daily. Reduce meal patterns could be attributed to ageing or disease related impairments in appetite, taste sensation, chewing, swallowing, digesting and absorbing nutrients ${ }^{43,44}$. Contrarily, older persons in Ghana have been shown to skip meals primarily due to lack of money $^{18}$ whereas daily meal frequency in other studies have been higher ${ }^{45,46}$. Therefore although nutrition knowledge of a quarter respondents was adequate, with about $60 \%$ of the elderly in urban Ghana reportedly food insecure ${ }^{18}$, food choices will largely depend on food availability and not knowledge on what is appropriate or inappropriate.

Undernutrition prevalence was $10 \%$ whereas $38 \%$ were overweight/obese. Although this is similar to the $12 \%$ underweight documented in Senegal ${ }^{11}$, it is far less than the $48 \%{ }^{11,17}$ and $41 \%{ }^{16}$ recorded in earlier studies in Ghana. In the Lake Victoria Basin of East Africa, underweight prevalence was $26 \%{ }^{15}$ whereas using the mini-nutritional assessment tool, $28.4 \%$ of older persons age 65 to 88 years were malnourished in DR Congo ${ }^{47}$. Conversely, overweight/obesitylevels were 20\%-points higher than the $17 \%$ documented by Blankson and Hall in Ghana ${ }^{16}$.
Their studies were conducted among old old' and 'oldest old' rural and institutionalized urban elderly dwellers, known to be at highest risk of undernutrition. After 70 years, some weight loss occurs and is attributed to the aging process itself. The implication of this idiopathic weight loss is higher levels of underweight with advancing age. Waist circumference gives a better indication of adiposity and sarcopenic obesity ${ }^{48}$ as there is usually some height loss with ageing ${ }^{32}$. Therefore it could have been a better nutritional status indicator. The global epidemiological transition caused by urbanization, reduced physical activity, low consumption of whole grains, fruits and vegetables and increased intake of fats/oils, sugar-sweetened beverages, is evident in Ghana ${ }^{21,49}$. The consequent effect is a shift from undernutrition to obesity as seen in this study.

Even though correlations between nutrition knowledge and dietary intakes and between nutrition knowledge and nutritional status were positive, the associations were weak and insignificant. However, a systematic review has reported a significant but weak positive associations between nutrition knowledge and dietary intake ${ }^{30}$. A plausible explanation for the knowledge not translating into practice in our study might be the physical discomforts that reportedly characterized the feeding of majority of the respondent contributing to meal skipping. Also, lack of regular income influences one's ability to purchase nutritious diversified diets. This aggravates the food insecurity situation observed by Steiner-Asiedu et al among the elderly in Ghana ${ }^{18}$. Aside appetite and hunger, availability of food and money ranked high in determining respondents' food choices. This buttresses the impact of socio-economic status and food security on dietary intakes and consequently nutritional status.

Associations between dietary patterns and nutritional status have generally been inconsistent ${ }^{50}$. From this study, the positive relationship found between nutritional status and diet quality suggests that healthy dietary intakes could contribute to the achievement of optimum nutritional status in older persons as documented in other studies ${ }^{51,52}$. The key limitation of this study is the use of non-probability sampling procedures in participant selection. It does not allow for generalization of findings to the general population. Findings also provide little evidence of 
causality because the likelihood of non-random sampling eliminating confounding variables within the study itself is low. Also, participant recruitment is prone to selection bias. This could affect accuracy of the nutritional status estimates and contribute to a distortion in the measure of association. Again, because rigorous socio-economic status indicators (SES) were not employed, it is difficult to establish the relationship between SES, diet quality and nutritional status. Nevertheless, this is one of the few studies conducted among free community-dwelling ambulatory 'young old' adults resident in peri-urban areas of Ghana. This study has provided new insights not only on the quality of diets consumed but reaffirmed the emergent nutrition and epidemiological transition even among the ageing population in Ghana.

\section{Conclusion}

Majority of the respondents had satisfactory to adequate knowledge on nutrition issues as relate to the elderly. However, this knowledge neither translated to improved dietary intakes nor optimum nutritional status. Conversely, adequate dietary intakes correlated positively with nutrition status. Although access to health-promoting information is vital for lifestyle modification, this study has reaffirmed that adequate nutrition knowledge does not necessarily imply an improvement in dietary intakes. To encourage and facilitate healthy dietary habits in older people requires family support, nutrition-sensitive social interventions and safety net for the elderly to ensure household food security.

\section{Competing interest}

The authors declare that they have no competing interests.

\section{Funding}

We did not receive any funding for this research.

\section{Acknowledgement}

Heartfelt thanks to Ms. Deepak Kumar of the University of Chester for assisting in drafting portions of the manuscript.

\section{References}

1. Roberts SB, Rosenberg I. Nutrition and aging: changes in the regulation of energy metabolism with aging. Physiological reviews. 2006;86(2):651-67.
2. Carstensen LL. Our Aging Population-It May Just Save us All. The Upside of Aging: How Long Life is Changing the World of Health, Work, Innovation, Policy, and Purpose. 2014:1-18.

3. WHO. Ageing and Life Course. Facts about aging Geneva, Switzerland World Health Organization http:// www.who.int/ageing/about/facts/en/; 2014 [cited 2015 01/08/15].

4. Ghana Statistical Service. 2010 POPULATION \& HOUSING CENSUS REPORT. The elderly in Ghana Accra, Ghana: Ghana Statistical Service http://www. statsghana.gov.gh/docfiles/publications/2010phc_the_ elderly_in_Gh.pdf, 2013.

5. WHO. A glossary of terms for community health care and Services for older persons Geneva, Switzerland World Health Organization Centre for Health Development Ageing and Health Technical Report Volume 5 http:// www.who.int/kobe_centre/ageing/ahp_vol5_glossary. pdf, 2004.

6. Vellas B, Gillette-Guyonnet S, Nourhashemi F, Rolland Y, Lauque S, Ousset P, et al. Falls, frailty and osteoporosis in the elderly: a public health problem. La Revue de medecine interne/fondee par la Societe nationale francaise de medecine interne. 2000;21(7):608-13.

7. Munkyong Pae SNM, Dayong Wu. The Role of Nutrition in Enhancing Immunity in Aging. A\&amp;D. 2012;3(1):91-129.

8. Jyrkkä J, Enlund H, Lavikainen P, Sulkava R, Hartikainen S. Association of polypharmacy with nutritional status, functional ability and cognitive capacity over a three-year period in an elderly population. Pharmacoepidemiology and drug safety. 2011;20(5):514-22.

9. Chilima D. Assessing nutritional status and functional ability of older adults in developing countries. Development in Practice. 2000;10(1):108-13.

10. Anderson AL, Harris TB, Tylavsky FA, Perry SE, Houston DK, Hue TF, et al. Dietary patterns and survival of older adults. Journal of the American Dietetic Association. 2011;111(1):84-91.

11. Kimokoti RW, Hamer DH. Nutrition, health, and aging in sub-Saharan Africa. Nutrition reviews. 2008;66(11):611 PubMed -23.

12. Donini LM, Scardella P, Piombo L, Neri B, Asprino $\mathrm{R}$, Proietti A, et al. Malnutrition in elderly: social and economic determinants. The journal of nutrition, health \& aging. 2013;17(1):9-15.

13. Nazemi L, Skoog I, Karlsson I, Hosseini S, Moham-

African Health Sciences Vol 18 Issue 3, September, 2018 
madi MR, Hosseini M, et al. Malnutrition, Prevalence and Relation to Some Risk Factors among Elderly Residents of Nursing Homes in Tehran, Iran. Iranian journal of public health. 2015;44(2):218.

14. van Nie-Visser NC, Meijers J, Schols J, Lohrmann C, Bartholomeyczik S, Spreeuwenberg M, et al. Which characteristics of nursing home residents influence differences in malnutrition prevalence? An international comparison of The Netherlands, Germany and Austria. The British journal of nutrition. 2014;111(6):1129-36.

15. Cheserek MJ, Tuitoek P, Waudo J, Msuya JM, Kikafunda JK. Anthropometric characteristics and nutritional status of older adults in the Lake Victoria Basin of East Africa: region, sex, and age differences. South African Journal of Clinical Nutrition. 2012;25(2):67-72.

16. Blankson B, Hall A. The anthropometric status of elderly women in rural Ghana and factors associated with low body mass index. The journal of nutrition, health $\&$ aging. 2012;16(10):881 PubMed -6.

17. Tayie F, Adjetey-Sorsey E, Armah J, Busolo D, Imaya E. Prevalence of undernutrition among elderly persons in Accra. Ghana Medical Journal. 2006;38(2):51-5.

18. Steiner-Asiedu M, Mombo Pelenah, J., Bediako-Amoa, B., Danquah, A. The Nutrition Situation of the Elderly in Ghana: A Case Study. Asian Journal of Medical Sciences. 2010;2:95-103.

19. Ayernor PK. Diseases of Ageing in Ghana. Ghana Medical Journal. 2012;46(2):18-22.

20. Minicuci N, Biritwum RB, Mensah G, Yawson AE, Naidoo N, Chatterji S, et al. Sociodemographic and socioeconomic patterns of chronic non-communicable disease among the older adult population in Ghana. Global health action. 2014;7.

21. Agyei-Mensah S, de-Graft Aikins A. Epidemiological Transition and the Double Burden of Disease in Accra, Ghana. Journal of urban health. 2010;87(5):879-97.

22. Nykänen I, Rissanen T, Sulkava R, Hartikainen S. Effects of individual dietary counseling as part of a Comprehensive Geriatric Assessment (CGA) on nutritional status: A population-based intervention study. The journal of nutrition, health \& aging. 2014;18(1):54 PubMed $-8$.

23. Sahyoun NR, Pratt CA, Anderson A. Evaluation of nutrition education interventions for older adults: a proposed framework. Journal of the American Dietetic Association. 2004;104(1):58-69.

24. Bandayrel K, Wong S. Systematic literature review of randomized control trials assessing the effectiveness of nutrition interventions in community-dwelling older adults. Journal of nutrition education and behavior. 2011;43(4):251-62.

25. ShatensteinB, Ferland G, Belleville S, Gray-Donald K, Kergoat M-J, Morais J, et al. Diet quality and cognition among older adults from the NuAge study. Experimental gerontology. 2012;47(5):353-60.

26. McNaughton SA, Bates CJ, Mishra GD. Diet quality is associated with all-cause mortality in adults aged 65 years and older. The Journal of nutrition. 2012;142(2):320-5.

27. Santos D, Rodrigues S, De Oliveira B, De Almeida MV. Diet quality in elderly Portuguese households. The journal of nutrition, health \& aging. 2014;18(3):243-50.

28. Irz X, Fratiglioni L, Kuosmanen N, Mazzocchi M, Modugno L, Nocella G, et al. Sociodemographic determinants of diet quality of the EU elderly: a comparative analysis in four countries. Public Health Nutrition. 2014;17(05):1177-89.

29. Lin W, Lee Y-W. Nutrition knowledge, attitudes and dietary restriction behaviour of Taiwanese elderly. Asia Pacific journal of clinical nutrition. 2005;14(3):221-9.

30. Spronk I, Kullen C, Burdon C, O'Connor H. Relationship between nutrition knowledge and dietary intake. British Journal of Nutrition. 2014;111(10):1713-26.

31. Ghana Statistical Service. 2010 Population and housing census. District analytical report. Ga West municipality. Accra, Ghana http://www.statsghana.gov.gh/docfiles/2010_District_Report/Greater $\% 20$ Accra/GA\%20 WEST.pdf:Ghana Statistical Service, , 2014.

32. Videman T, Battié MC, Gibbons LE, Gill K. Aging changes in lumbar discs and vertebrae and their interaction: a 15-year follow-up study. The Spine Journal. 2014;14(3):469-78.

33. Cochran WG. Sampling techniques: John Wiley \& Sons; 2007.

34. WHO. Obesity: preventing and managing the global endemic WHO: Geneva, Switzerland: World Health Organization http://apps.who.int/iris/ bitstream/10665/42330/1/WHO_TRS_894.pdf?ua $=1 \& u a=1,2000$.

35. Jain M, Purnima PJ, Gupta K. Appraisal of Nutrition and Health Related Knowledge, Attitude and Practices of Rural and Urban Elderly Using A Gender Lens. Indian Journal of. 2013;27(3):519 PubMed -29.

36. Yin Z, Geng G, Lan X, Zhang L, Wang S, Zang Y, et al. Status and determinants of health behavior knowl- 
edge among the elderly in China: a community-based cross-sectional study. BMC public health. 2013;13(1):710 PubMed .

37. SantosD, Oliveira B, Rodrigues S, De Almeida M. Effect of sociodemographic variables and time on food group contribution to total food availability in Portuguese elderly households. The journal of nutrition, health \& aging. 2014;18(5):471-8.

38. Kiefte-de Jong JC, Mathers JC, Franco OH. Nutrition and healthy ageing: the key ingredients. Proceedings of the Nutrition Society. 2014;73(02):249-59.

39. Shatenstein B, Gauvin L, Keller H, Richard L, Gaudreau P, Giroux F, et al. Baseline determinants of global diet quality in older men and women from the NuAge cohort. The journal of nutrition, health \& aging. 2013;17(5):419 PubMed -25.

40. Ramic E, Pranjic N, Batic-Mujanovic O, Karic E, Alibasic $\mathrm{E}$, Alic A. The effect of loneliness on malnutrition in elderly population. Med Arh. 2011;65(2):92 PubMed -5 .

41. Tani Y, Kondo N, Takagi D, Saito M, Hikichi H, Ojima $\mathrm{T}$, et al. Combined effects of eating alone and living alone on unhealthy dietary behaviors, obesity and underweight in older Japanese adults: Results of the JAGES. Appetite. 2015;95:1-8.

42. Pilgrim AL, Robinson SM, Sayer AA, Roberts HC. An overview of appetite decline in older people. Nursing Older People. 2015;27(5):29-35.

43. Elmadfa I, Meyer AL. Body Composition, Changing Physiological Functions and Nutrient Requirements of the Elderly. Annals of Nutrition and Metabolism. 2008;52(suppl 1)(Suppl. 1):2-5.

44. Kalyan G, Sarin J, Gulia R, Rani R, Malik R. Diet Associated Problems and Nutritional Status of Elderly of Selected Community of District Ambala, Haryana. Nursing and Midwifery Research. 2015;11(2):78.
45. Mekary RA, Giovannucci E, Cahill L, Willett WC, van Dam RM, Hu FB. Eating patterns and type 2 diabetes risk in older women: breakfast consumption and eating frequency. The American journal of clinical nutrition. 2013;98(2):436-43.

46. Mekary RA, Giovannucci E, Willett WC, van Dam RM, $\mathrm{Hu}$ FB. Eating patterns and type 2 diabetes risk in men: breakfast omission, eating frequency, and snacking. The American journal of clinical nutrition. 2012;95(5):1182-9. 47. Andre MB, Dumavibhat N, Eitoku M, Hirota R, Suganuma N. Mini Nutritional Assessment and functional capacity in community-dwelling elderly in Rural Luozi, Democratic Republic of Congo. Geriatrics \& gerontology international. 2013;13(1):35-42.

48. Ashwell M, Gunn P, Gibson S. Waist-to-height ratio is a better screening tool than waist circumference and BMI for adult cardiometabolic risk factors:systematic review and meta-analysis. Obesity reviews. 2012;13(3):275-86.

49. Popkin BM, Adair LS, Ng SW. Global nutrition transition and the pandemic of obesity in developing countries. Nutrition reviews. 2012;70(1):3 PubMed -21.

50. Cutler GJ, Flood A, Hannan PJ, Slavin JL, Neumark-Sztainer D. Association between major patterns of dietary intake and weight status in adolescents. British Journal of Nutrition. 2012;108(02):349-56.

51. Ford DJ, Jensen GL, Bailey R, Smiciklas-Wright H, Erickson P, Wood C, et al. The association between diet quality, BMI and health-related quality of life in the Geisinger Rural Aging Study (GRAS). The FASEB Journal. 2013;27(1_MeetingAbstracts):245.1.

52. Boggs DA, Rosenberg L, Rodríguez-Bernal CL, Palmer JR. Long-term diet quality is associated with lower obesity risk in young African American women with normal BMI at baseline. The Journal of nutrition. 2013;143(10):1636-41. 